\title{
Study on Optimal Placement and Reasonable Number of Viscoelastic Dampers by Improved Weight Coefficient Method
}

\author{
Ji-ting Qu ${ }^{1,2}$ and Hong-nan $\mathrm{Li}^{1}$ \\ ${ }^{1}$ Faculty of Infrastructure Engineering School of Civil Engineering, Dalian University of Technology, Dalian 116024, China \\ ${ }^{2}$ State Key Laboratory of Structural Analysis for Industrial Equipment, Dalian University of Technology, Dalian 116024, China \\ Correspondence should be addressed to Ji-ting Qu; qjt@dlut.edu.cn
}

Received 19 July 2013; Revised 18 November 2013; Accepted 18 November 2013

Academic Editor: Gangbing Song

Copyright (C) 2013 J.-t. Qu and H.-n. Li. This is an open access article distributed under the Creative Commons Attribution License, which permits unrestricted use, distribution, and reproduction in any medium, provided the original work is properly cited.

\begin{abstract}
A new optimal method is presented by combining the weight coefficient with the theory of force analogy method. Firstly, a new mathematical model of location index is proposed, which deals with the determination of a reasonable number of dampers according to values of the location index. Secondly, the optimal locations of dampers are given. It can be specific from stories to spans. Numerical examples are illustrated to verify the effectiveness and feasibility of the proposed mathematical model and optimal method. At last, several significant conclusions are given based on numerical results.
\end{abstract}

\section{Introduction}

Structural control protects structures and resists earthquakes by placing many types of energy dissipaters. Several passive as well as active methods and techniques have been developed [1-7]. Viscoelastic dampers (VED) have shown to be effective energy dissipation devices for structures under wind and seismic actions. To design a structure with energy dissipation devices, the placement of dampers has moderate influence on structural responses and the achievement of design objectives. Up to now, various methods in placing dampers have been studied, such as topological optimization [8], simulated annealing optimization [9], gradient-based method [10, 11], and genetic algorithm $[12,13]$. These approaches usually do the step-by-step time history analysis many times by the circulation approximation when they are applied to the optimal placement of dampers for high-rise structures.

As an effective method among them, Zhang et al. [14] suggested a weight coefficient method for choosing parameters and locations of VEDs. On the premise that the amount of dampers is fixed, the number of dampers located on each story can be determined according to the ratio of the control indices of each story to the sum of them. This method is advantageous to calculate the number of dampers placed on each story all at once and bring great applicability in highrise structures with energy dissipation devices. However, this method is introduced for placing dampers on stories on the assumption of a certain amount of dampers and hardly can provide basis and recommendation on the placement in spans.

The force analogy method (FAM) was first proposed by Lin [15] for the inelastic analysis in continuum mechanics. Hart and Wong [16] extended this method into the dynamic analysis of nonlinear structures, while Wong and Yang [17] proposed a new algorithm based on this method formulated in the force-deformation space for inelastic dynamic analysis. The state space approach is mainly used in the FAM, which is a kind of time domain method based on state variables in modern control theories and is quite convenient for the time history analysis. Except the structural response history, the rotation history and hysteretic loops of plastic hinges are also available according to the FAM, thus providing possibilities of analysis for strain-softening and elastic-plastic properties, in which traditional methods cannot be completed. Besides, the plastic energy dissipation can be determined on each component. Combined with the hysteretic loops of dissipation devices, plastic hinges' transformations and order of appearance could be monitored for structures under earthquake excitations [18].

The main objective of this research is to study the optimization of VEDs. The weight coefficient method is improved based on the FAM theory and a new mathematical model of 
location optimization will be established, which is suitable for determining the amount of dampers and the specific location of VEDs in spans. Numerical analyses are illustrated to verify effectiveness and feasibility of the improved method and the new location index for the optimization of dampers and structural control, which supplies beneficial reference to further optimizations.

\section{Energy Equation in Force Analogy Method}

2.1. Principle of Force Analogy Method. The fundamental principle of the FAM is that each inelastic deformation is formulated as a degree of freedom and the force is calculated through varying displacement instead of varying stiffness, which means that the initial stiffness matrix can be used throughout the inelastic analysis. The FAM uses inelastic displacement as the variable rather than stiffness, with high efficiency and accuracy in analyzing inelastic responses. It is the premise of the theory that the whole deformation can be considered as the accumulation of local deformation. Plastic hinges are used to simulate structural plasticity in this method.

The basic concept of the FAM was presented in detail by Wong and Yang [17] in the analysis of braced frames, so only a brief summary is provided as background. Studying from a single degree of freedom system (SDOF), the inelastic responses are expressed by varying a displacement field as shown in Figure 1. In this figure, the total displacement $x(t)$ because of external force $F(t)$ is divided into two parts: the elastic displacement $x^{\prime}(t)$ and the inelastic displacement $x^{\prime \prime}(t)$. The inelastic deformation of the structure is considered to be concentrated on the ends of the beams and columns, which is presented by the inelastic rotation of the plastic hinge $\theta^{\prime \prime}(t)$. The restoring force in the system $F_{s}(t)$ is written as

$$
\begin{gathered}
F_{s}=k_{e} x_{y}+k_{t}\left(x-x_{y}\right), \\
x^{\prime}=\frac{F_{s}}{k_{e},} \\
x^{\prime \prime}= \begin{cases}0, & x<x_{y}, \\
\left(x-x_{y}\right)\left(1-\frac{k_{t}}{k_{e}}\right), & x>x_{y},\end{cases}
\end{gathered}
$$

where $k_{e}$ and $k_{t}$ denote the initial and postyield stiffness, respectively and $x_{y}$ and $F_{y}$, respectively, represent the yield displacement and yield force.

Then, the total moment $M(t)$ at the locations where plastic hinges may form can be expressed as

$$
M(t)=M^{\prime}(t)+M^{\prime \prime}(t)=\frac{3 E I}{l^{2}} x(t)-\frac{3 E I}{l} \theta^{\prime \prime}(t),
$$

where $M^{\prime}(t)$ denotes the elastic moment caused by elastic displacement and $M^{\prime \prime}(t)$ represents the residual moment because of inelastic displacement.
2.2. Energy Equations of Structures. The equation of motion for an $n$-degree-freedom structure subjected to an earthquake can be written as

$$
M \ddot{X}(t)+C \dot{X}(t)+K X^{\prime}(t)=-M \ddot{X}_{g}(t),
$$

where $M$ and $C$ mean the $n \times n$ mass and inherent damping matrices of the structure, $X^{\prime}(t)$ is the $n$-dimensional elastic displacement vector, $\dot{X}(t)$ and $\ddot{X}(t)$ are the relative velocity and acceleration vector of the $n$-dimension, and $\ddot{X}_{g}(t)$ implies the seismic excitation.

Define the absolute acceleration $\ddot{Y}(t)$ to be the sum of $\ddot{X}(t)$ and $\ddot{X}_{g}(t)$. Based on the structural dynamic equation under earthquakes and the fundamental principle of FAM, the energy equation can be gained as follows:

$$
\begin{gathered}
\int_{t=0}^{t=t_{k}} \ddot{Y}^{T} M d Y+\int_{t=0}^{t=t_{k}} \dot{X}^{T} C d X+\int_{t=0}^{t=t_{k}} X^{\prime T} K d X^{\prime} \\
\quad+\int_{t=0}^{t=t_{k}} M^{\prime T} d \theta^{\prime \prime}=\int_{t=0}^{t=t_{k}} \ddot{Y}^{T} M d X_{g} .
\end{gathered}
$$

The above equation shows the different forms of energy in the structure. They are the kinetic energy, damping energy, strain energy, plastic energy (PE), and input energy from left to right. Studies show that the input energy will be dissipated by the plastic energy and strain energy, and plastic energy is dissipated due to the development of plastic hinges, which can be viewed as

$$
\begin{aligned}
\mathrm{PE} & =\int_{t=0}^{t=t_{k}} M^{\prime T} d \theta^{\prime \prime} \\
& =\int_{t=0}^{t=t_{k}} \sum_{i=1}^{m} M_{i}^{\prime T} d \theta_{i}^{\prime \prime}=\sum_{i=1}^{m} \mathrm{PE}_{i},
\end{aligned}
$$

where $\mathrm{PE}_{i}$ represents the plastic dissipation of the $i$ th plastic hinge. For structures with dissipation devices, hysteretic loops of these devices and plastic dissipation of each plastic hinge can be gained using the force analogy method, which makes the energy specified. Plastic hinges may be overdeformed, leading to structural failure when subjected to a large earthquake. Thus, passive energy dissipation devices like the VEDs are used in structures to absorb energy from earthquakes.

\section{Improved Weight Coefficient Method}

3.1. Objective Function. To bring forward an objective function is a core concept in optimal design. To design a structure with energy dissipation devices, the optimal location of dampers can make the performance indices be restricted within desired objectives as the amount of dampers is fixed. The performance index of the weight coefficient method is the story-drift angle. On the premise that the number of dampers is fixed, the number of dampers placed on the $i$ th story can be determined by

$$
N_{i}=N \frac{\theta_{i}}{\sum_{i=1}^{n} \theta_{i}},
$$




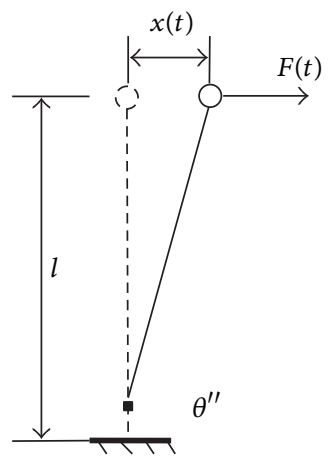

(a) Deformation of SDOF model

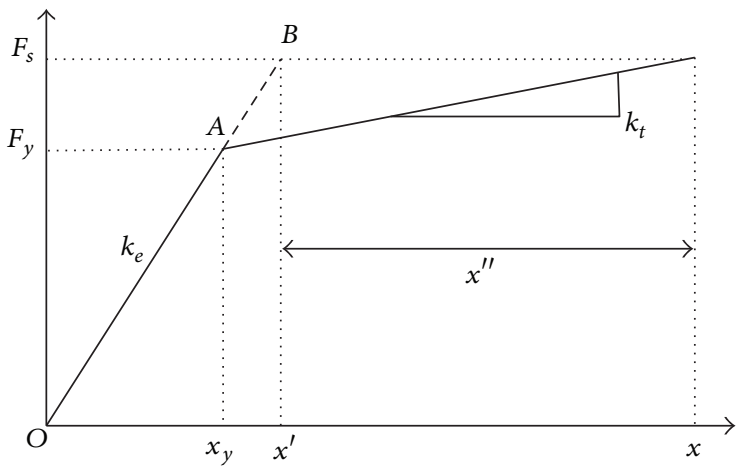

(b) Force-displacement relationship

Figure 1: The principle of FAM. where $N$ is the amount of VEDs needed to be located on the whole structure, $n$ is the number of stories, and $\theta_{i}$ represents the drift angle of the $i$ th story. The number of dampers placed on the story can be calculated by using the above formulation of the weight coefficient method on the assumption of $N$, but the specific locations of them in spans are not determined.

Combining the weight coefficient method with the force analogy method, in this paper, a new objective function of optimal location for the VEDs is proposed. The aim is to place dampers on the locations where the hysteretic energy dissipation is large. Because the hysteretic energy dissipation is considered as the sum of the plastic energy of each member in the FAM, the plastic energy due to the inelastic deformation of each span is taken as the performance index which can be evaluated using the FAM. The optimal index can be written in the following form:

$$
\rho_{l}=\frac{w_{l}}{\max \left(w_{i}\right)} \quad(i=1,2, \ldots, r),
$$

where $w_{l}$ denotes the sum of plastic energy of two beam ends on the $l$ th $\operatorname{span}, \max \left(w_{i}\right)$ represents the maximum value of plastic energy of all the spans, $r$ is the number of spans of a structure, and $\rho_{l}$ denotes the objective function of the $l$ th span. The values of the optimal index can be calculated for the structure subjected to earthquakes according to Section 2 .

For the case that the location index $\rho_{l}$ is greater than or equal to different values, the amount of dampers $N$ needed to be placed on the structure can be determined. The number of dampers on each story can be calculated all at once based on the principle of the weight coefficient method in the following form:

$$
\begin{gathered}
N_{k}=N \frac{W_{k}}{\sum_{i=1}^{n} W_{i}}, \\
W_{k}=\sum_{i=1}^{m} w_{i},
\end{gathered}
$$

where $m$ means the number of spans of each story and $W_{k}$ represents the total plastic energy of the $k$ th story.
At last, the specific location of dampers in each span can be determined according to the number of dampers on each story and the value of the location index. In other words, the dampers should be arranged in the span where the index values are larger.

3.2. Optimal Design Process Based on Improved Weight Coeffcient. Based on the improved weight coefficient method and the process of dynamic analysis of the structures, the steps of the optimal design process are as follows.

(1) Do step-by-step time history analysis of system without dampers by inputting records of earthquakes.

(2) Calculate the values of optimal indices of all spans according to formula (7).

(3) Set a target value of the location index according to the target of damping rate and determine the amount of dampers for the structure.

(4) Confirm the number of dampers on each story by using formulae (8).

(5) Make certain of the specific location of dampers according to the values of the position index and the number of each story.

(6) Do step-by-step time history analysis of the controlled structure with dampers subjected to earthquakes and analyze whether or not the effective reduction of structural responses is satisfied.

The system analysis and optimal design procedures of dampers are programmed by adopting the MATLAB programming language.

\section{Numerical Analysis}

4.1. Structural Model. A 15-story, 3-span moment resisting frame [19] is considered. The serial number of plastic hinges and spans of the structure is shown in Figure 2. The mechanical properties are provided in Table 1 . The mass is $56,430 \mathrm{~kg}$ of each floor, the span is $6.6 \mathrm{~m}$, and the height of each story is $3.3 \mathrm{~m}$. The stress-strain relation of steel is considered to 


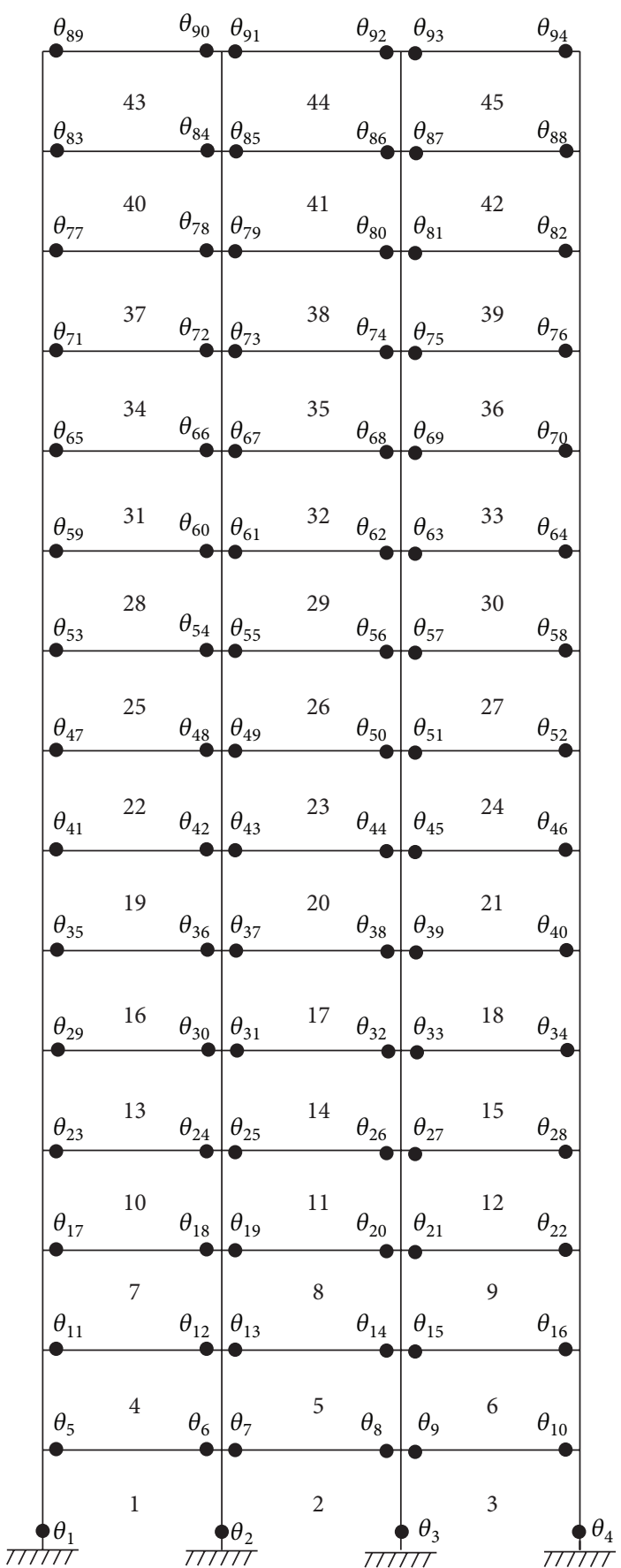

FIgURE 2: The serial number of plastic hinges and spans of the structure.

be ideal elastic-plastic with the modulus of elasticity $E=$ $2.06 \times 10^{7} \mathrm{~N} / \mathrm{mm}$. The yield stress of the steel members is $345 \mathrm{MPa}$. The increase of strength caused by strain-hardening and axial deformations is ignored.

4.2. Earthquake Records. Four seismic records are chosen as the input earthquake ground accelerations to the structure in this paper as shown in Table 2. The values of peak ground accelerations are scaled to $400 \mathrm{gal}, 1200 \mathrm{gal}, 600 \mathrm{gal}$, and
TABLE 1: Mechanical properties of the structure.

\begin{tabular}{lcc}
\hline Member & Type of section & Material \\
\hline Columns of 1 3 story & $\mathrm{H} 400 \times 400 \times 30 \times 50$ & \\
Columns of $4 \sim 5$ story & $\mathrm{H} 400 \times 400 \times 25 \times 40$ & \\
Columns of $6 \sim 8$ story & $\mathrm{H} 400 \times 400 \times 20 \times 35$ & Q345 \\
Columns of 9 10 story & $\mathrm{H} 400 \times 400 \times 20 \times 32$ & \\
Columns of 11 15 story & $\mathrm{H} 400 \times 400 \times 18 \times 28$ & \\
Beams of 1 15 story & $\mathrm{H} 500 \times 300 \times 12 \times 25$ & \\
\hline
\end{tabular}

200 gal to make structures perform inelastically so as to calculate dampers' location indices.

4.3. Optimal Results. Compared with traditional energy analysis, the computational method based on the FAM is highly efficient and accurate. It utilizes the change in displacement to represent the inelastic behavior of the structure instead of changing stiffness. The plastic energy of each member is calculated according to Section 2.2 and the optimization process is programmed by adopting the MATLAB programming language.

Structural plastic energy is equal to the sum of individual plastic dissipations at each plastic hinge, which are computed by the MATLAB program. According to the index formula (7), location indices are calculated. For the case that the location index $\rho_{l}$ is greater than or equal to $0.8,0.6$ and 0.4 , the amount of dampers needed to be placed on the structure are 12,20 , and 24 , respectively, termed as cases 1,2 , and 3 . Take case 1 as an example, the calculation of optimal location is shown in Table 3. Compared with the original weight coefficient method, which can be applied on the premise that the number of dampers is fixed, the improved method can determine the reasonable number of dampers needed according to the location index and the engineering requirement.

The number of dampers placed on each story for three cases subjected to different earthquakes can be obtained as shown in Table 4. The results indicate that dampers are mainly located on the bottom and middle part of the structure for three cases. The number of dampers placed on the bottom and middle part increases with the addition of the amount from case 1 to 3 . But the effect on the placement of dampers on the top part of the structure is not obvious.

The results of location indices indicate that values of side spans are generally greater than middle spans on the bottom and middle part of the structure, which is the basis of position selection for each story. The zero value of the location index denotes that there is no plastic energy for the member end. In other words, the corresponding part yields no plastic hinges under the action of earthquakes. The optimal placement of dampers for three cases can be obtained according to the above results, as shown in Figures 3, 4, and 5.

The original weight coefficient method can only determine the number of dampers on each floor. For example, if two dampers are needed for the building on the first floor, the dampers are usually each placed on the side span according to experience. However, the improved method can determine 
TABLE 2: Earthquake records.

\begin{tabular}{lcccc}
\hline Records & Component & Interval $(\mathrm{s})$ & Time $(\mathrm{s})$ & Peak value $\left(\mathrm{cm} / \mathrm{s}^{2}\right)$ \\
\hline 1940, El Centro, CALIF & NS & 0.02 & 30 & 431.7 \\
1994, Northridge, Tarzana-Cedar Hill Nursery A & NS & 0.02 & 60 & 847.5 \\
1979, Imperial Valley, Superstition Mountain, CA & S45E & 0.02 & 28.34 & 146.4 \\
1976, Tianjin Hospital, Ninghe & NS & 0.01 & 19.19 & 145.8
\end{tabular}

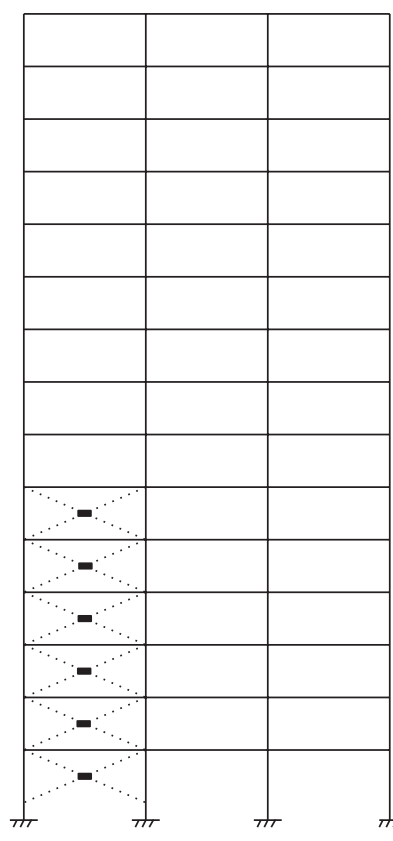

(a) El Centro

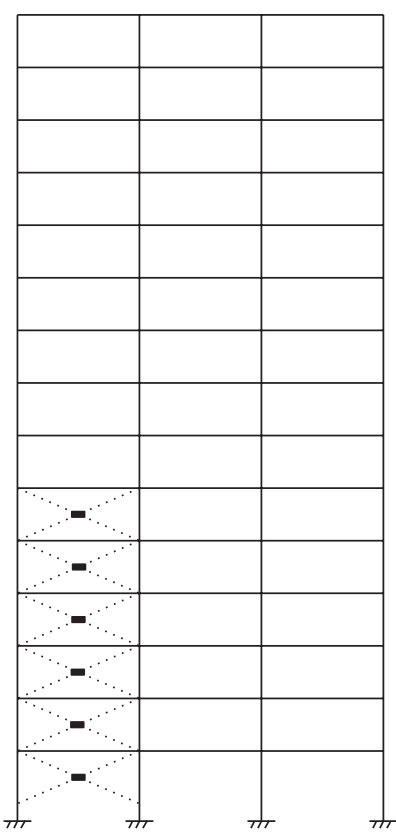

(b) Northridge

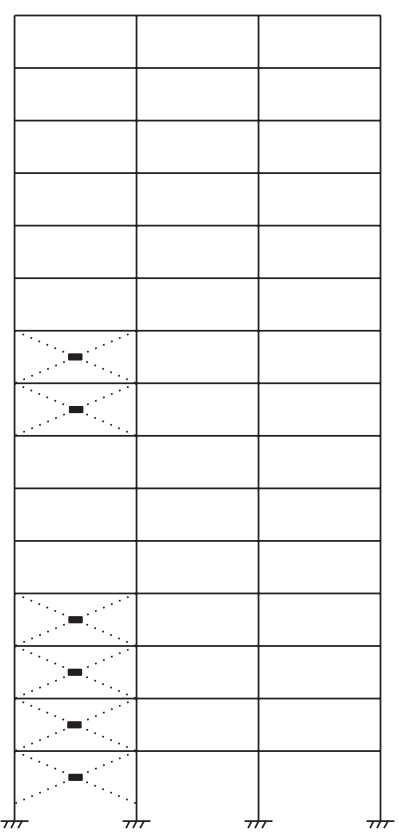

(c) Imperial Valley

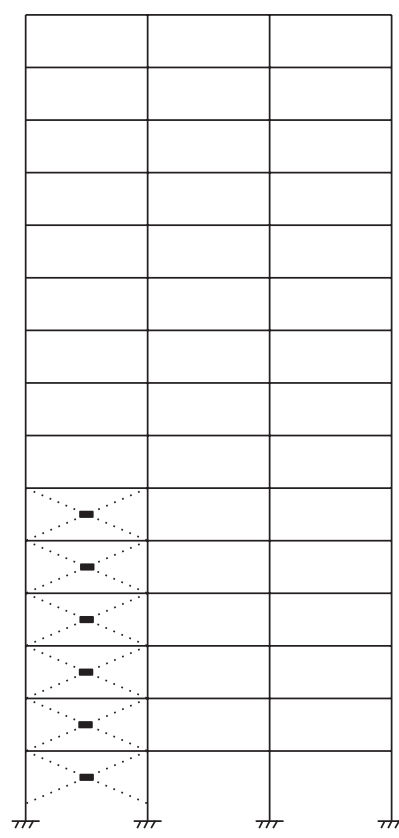

(d) Tianjin

FIGURE 3: Optimal location of dampers for case 1.

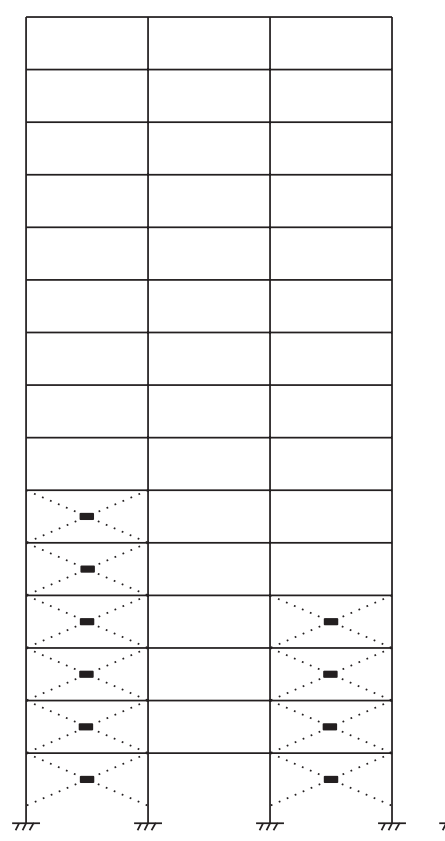

(a) El Centro

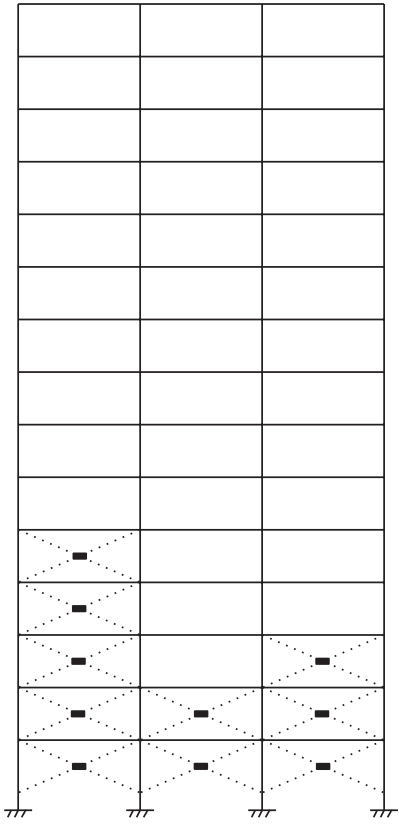

(b) Northridge

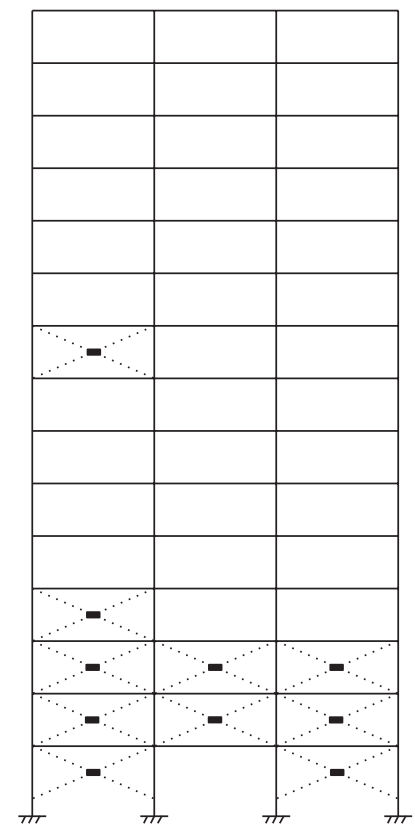

(c) Imperial Valley

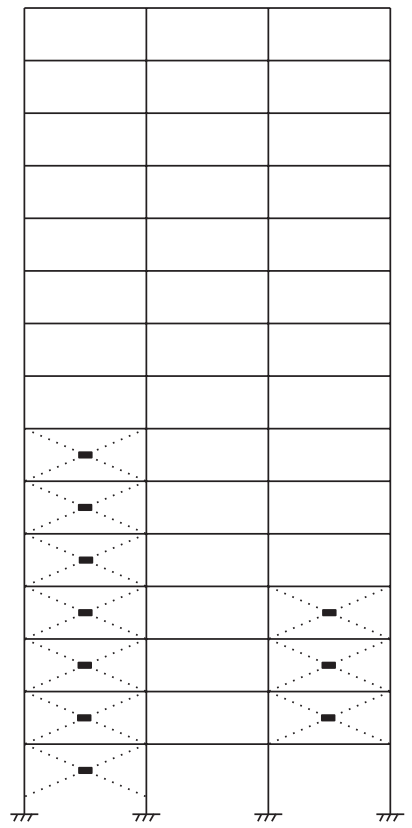

(d) Tianjin

Figure 4: Optimal location of dampers for case 2. 
TABLE 3: Optimal calculation for case 1.

\begin{tabular}{|c|c|c|c|c|c|c|}
\hline Story & Earthquake & $W_{k}$ & $\sum_{i=1}^{n} W_{i}$ & $W_{k} / \sum_{i=1}^{n} W_{i}$ & $N\left(W_{k} / \sum_{i=1}^{n} W_{i}\right)$ & $N_{k}$ \\
\hline \multirow{4}{*}{1} & El Centro & 130780 & 857718.6 & 0.15 & 1.83 & 2 \\
\hline & Northridge & 81339.5 & 308790.3 & 0.26 & 3.16 & 3 \\
\hline & Imperial Valley & 35064.82 & 145344.4 & 0.24 & 2.90 & 3 \\
\hline & Tianjin & 122828.9 & 889286.3 & 0.14 & 1.66 & 2 \\
\hline \multirow{4}{*}{2} & El Centro & 179236.4 & 857718.6 & 0.21 & 2.51 & 3 \\
\hline & Northridge & 104232.8 & 308790.3 & 0.34 & 4.05 & 3 \\
\hline & Imperial Valley & 46811.38 & 145344.4 & 0.32 & 3.86 & 3 \\
\hline & Tianjin & 177512.9 & 889286.3 & 0.20 & 2.40 & 2 \\
\hline \multirow{4}{*}{3} & El Centro & 170634.2 & 857718.6 & 0.20 & 2.39 & 2 \\
\hline & Northridge & 73045.34 & 308790.3 & 0.24 & 2.84 & 3 \\
\hline & Imperial Valley & 36157.5 & 145344.4 & 0.25 & 2.99 & 3 \\
\hline & Tianjin & 170438.9 & 889286.3 & 0.19 & 2.30 & 2 \\
\hline \multirow{4}{*}{4} & El Centro & 142590.5 & 857718.6 & 0.17 & 1.99 & 2 \\
\hline & Northridge & 33427.78 & 308790.3 & 0.11 & 1.30 & 2 \\
\hline & Imperial Valley & 17779.92 & 145344.4 & 0.12 & 1.47 & 2 \\
\hline & Tianjin & 143765.5 & 889286.3 & 0.16 & 1.94 & 2 \\
\hline \multirow{4}{*}{5} & El Centro & 96344.12 & 857718.6 & 0.11 & 1.35 & 1 \\
\hline & Northridge & 13383.64 & 308790.3 & 0.04 & 0.52 & 1 \\
\hline & Imperial Valley & 622.46 & 145344.4 & 0.00 & 0.00 & 0 \\
\hline & Tianjin & 114449.4 & 889286.3 & 0.13 & 1.54 & 2 \\
\hline \multirow{4}{*}{6} & El Centro & 64871.4 & 857718.6 & 0.08 & 0.91 & 1 \\
\hline & Northridge & 3361.22 & 308790.3 & 0.01 & 0.13 & 0 \\
\hline & Imperial Valley & 0 & 145344.4 & 0.00 & 0.00 & 0 \\
\hline & Tianjin & 77249.5 & 889286.3 & 0.09 & 1.04 & 1 \\
\hline \multirow{4}{*}{7} & El Centro & 42150.96 & 857718.6 & 0.05 & 0.59 & 1 \\
\hline & Northridge & 0 & 308790.3 & 0.00 & 0.00 & 0 \\
\hline & Imperial Valley & 555.78 & 145344.4 & 0.00 & 0.00 & 0 \\
\hline & Tianjin & 48947.2 & 889286.3 & 0.06 & 0.66 & 1 \\
\hline \multirow{4}{*}{8} & El Centro & 18588.14 & 857718.6 & 0.02 & 0.26 & 0 \\
\hline & Northridge & 0 & 308790.3 & 0.00 & 0.00 & 0 \\
\hline & Imperial Valley & 2315.88 & 145344.4 & 0.02 & 0.19 & 0 \\
\hline & Tianjin & 22726.54 & 889286.3 & 0.03 & 0.31 & 0 \\
\hline \multirow{4}{*}{9} & El Centro & 6705.2 & 857718.6 & 0.01 & 0.09 & 0 \\
\hline & Northridge & 0 & 308790.3 & 0.00 & 0.00 & 0 \\
\hline & Imperial Valley & 2974.04 & 145344.4 & 0.02 & 0.25 & 1 \\
\hline & Tianjin & 9685.74 & 889286.3 & 0.01 & 0.13 & 0 \\
\hline \multirow{4}{*}{10} & El Centro & 4511.84 & 857718.6 & 0.01 & 0.06 & 0 \\
\hline & Northridge & 0 & 308790.3 & 0.00 & 0.00 & 0 \\
\hline & Imperial Valley & 2424.72 & 145344.4 & 0.02 & 0.20 & 0 \\
\hline & Tianjin & 1681.68 & 889286.3 & 0.00 & 0.00 & 0 \\
\hline \multirow{4}{*}{11} & El Centro & 1305.86 & 857718.6 & 0.00 & 0.00 & 0 \\
\hline & Northridge & 0 & 308790.3 & 0.00 & 0.00 & 0 \\
\hline & Imperial Valley & 637.92 & 145344.4 & 0.00 & 0.05 & 0 \\
\hline & Tianjin & 0 & 889286.3 & 0.00 & 0.00 & 0 \\
\hline \multirow{4}{*}{12} & El Centro & 0 & 857718.6 & 0.00 & 0.00 & 0 \\
\hline & Northridge & 0 & 308790.3 & 0.00 & 0.00 & 0 \\
\hline & Imperial Valley & 0 & 145344.4 & 0.00 & 0.00 & 0 \\
\hline & Tianjin & 0 & 889286.3 & 0.00 & 0.00 & 0 \\
\hline
\end{tabular}


TABLe 3: Continued.

\begin{tabular}{|c|c|c|c|c|c|c|}
\hline Story & Earthquake & $W_{k}$ & $\sum_{i=1}^{n} W_{i}$ & $W_{k} / \sum_{i=1}^{n} W_{i}$ & $N\left(W_{k} / \sum_{i=1}^{n} W_{i}\right)$ & $N_{k}$ \\
\hline \multirow{4}{*}{13} & El Centro & 0 & 857718.6 & 0.00 & 0.00 & 0 \\
\hline & Northridge & 0 & 308790.3 & 0.00 & 0.00 & 0 \\
\hline & Imperial Valley & 0 & 145344.4 & 0.00 & 0.00 & 0 \\
\hline & Tianjin & 0 & 889286.3 & 0.00 & 0.00 & 0 \\
\hline \multirow{4}{*}{14} & El Centro & 0 & 857718.6 & 0.00 & 0.00 & 0 \\
\hline & Northridge & 0 & 308790.3 & 0.00 & 0.00 & 0 \\
\hline & Imperial Valley & 0 & 145344.4 & 0.00 & 0.00 & 0 \\
\hline & Tianjin & 0 & 889286.3 & 0.00 & 0.00 & 0 \\
\hline \multirow{4}{*}{15} & El Centro & 0 & 857718.6 & 0.00 & 0.00 & 0 \\
\hline & Northridge & 0 & 308790.3 & 0.00 & 0.00 & 0 \\
\hline & Imperial Valley & 0 & 145344.4 & 0.00 & 0.00 & 0 \\
\hline & Tianjin & 0 & 889286.3 & 0.00 & 0.00 & 0 \\
\hline
\end{tabular}

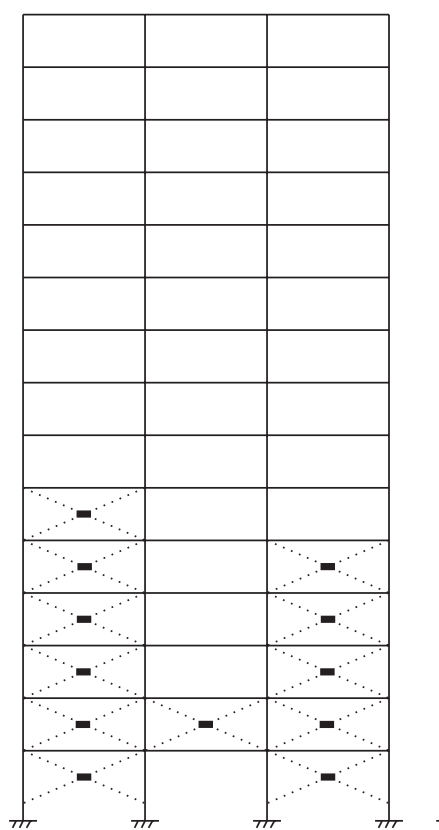

(a) El Centro

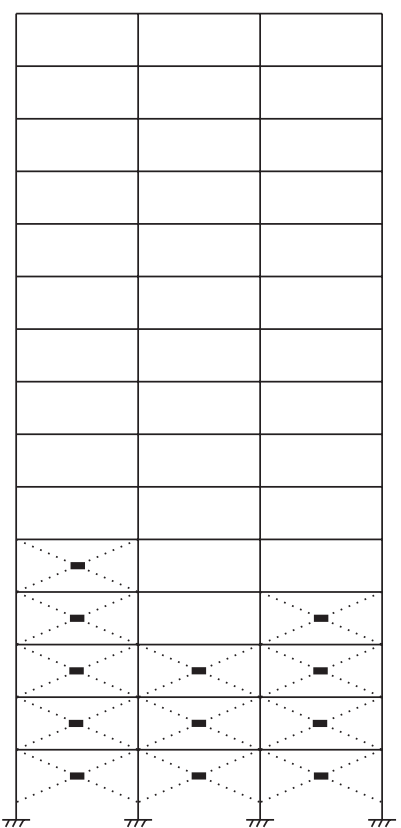

(b) Northridge

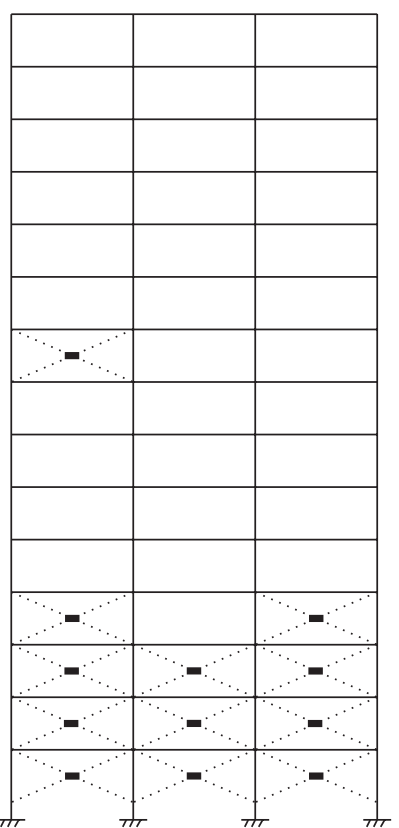

(c) Imperial Valley

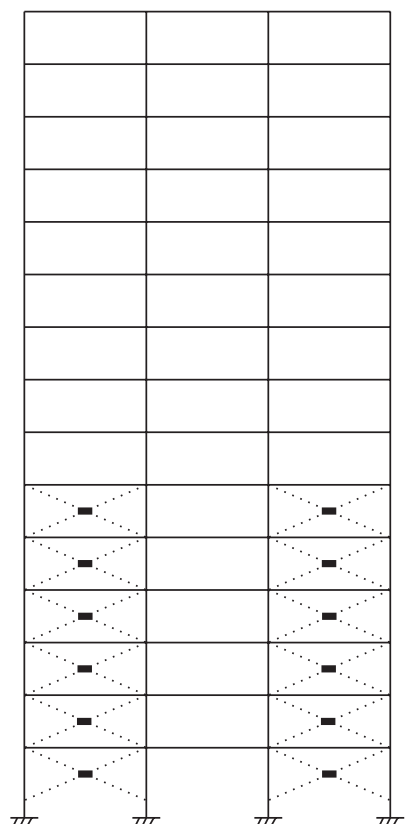

(d) Tianjin

FIgURE 5: Optimal location of dampers for case 3.

the specific location of dampers in spans according to the value of the location index.

4.4. Time History Analysis of the Structures with VEDs. A number of force-deformation relationship models of VEDs have been brought forward and they are applicable to different conditions. The Maxwell model is adopted. When the dampers are located in structures according to the optimal results, the step-by-step time history analysis is utilized by using the SAP 2000 to obtain the responses of structures for each of the three cases. The maximum displacements of the structure with and without dampers are compared as shown in Figure 6. The story drifts of the structure with optimally located dampers are calculated as shown in Tables 5, 6, and
7. The story drifts of the structure with and without dampers are compared as shown in Figure 7.

From the view of the above tables and figures, structural displacements are controlled well and decrease obviously when dampers are placed optimally. Also, the displacement distributions are more even. For case 1, the story drifts of the controlled structure decrease by $20 \% \sim 35 \%$, while for case 2 they decrease by $25 \% \sim 60 \%$ and for case 3 they decrease by $25 \% \sim 65 \%$. On the other hand, the more dampers used, the better the effect on energy dissipation of structures. Considering space limits and economy, the reasonable quantity of dampers can be determined by setting the feasible value of the location index to meet actual requirements. The value of the location index should be taken as 0.6 for the example for 


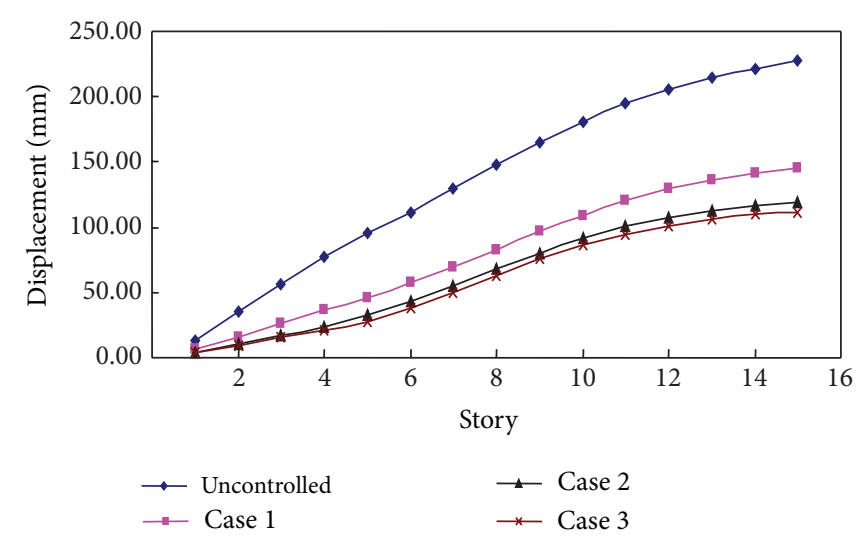

(a) El Centro

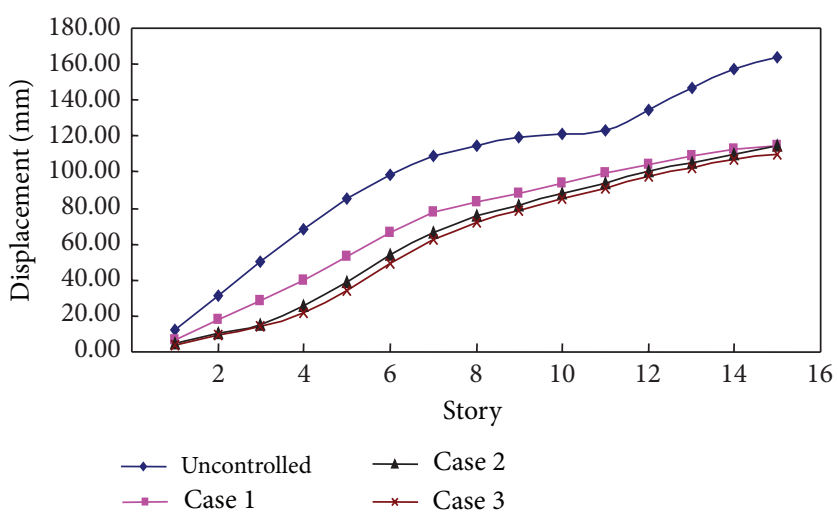

(c) Imperial Valley

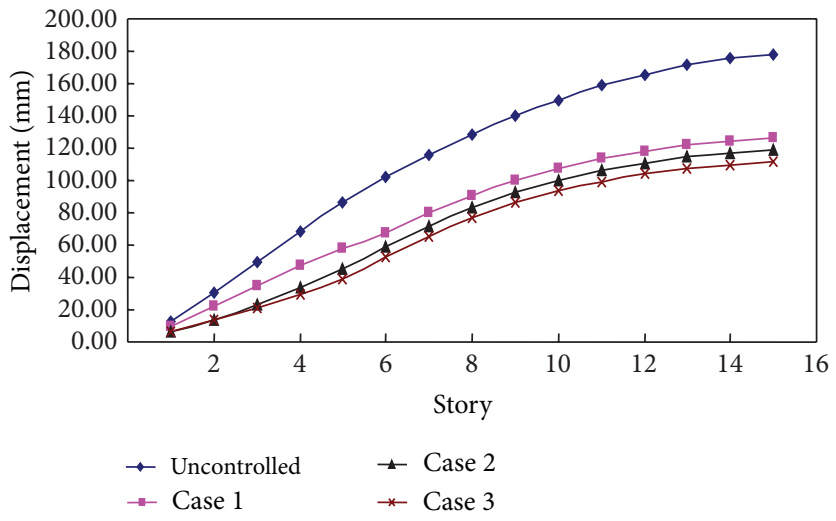

(b) Northridge

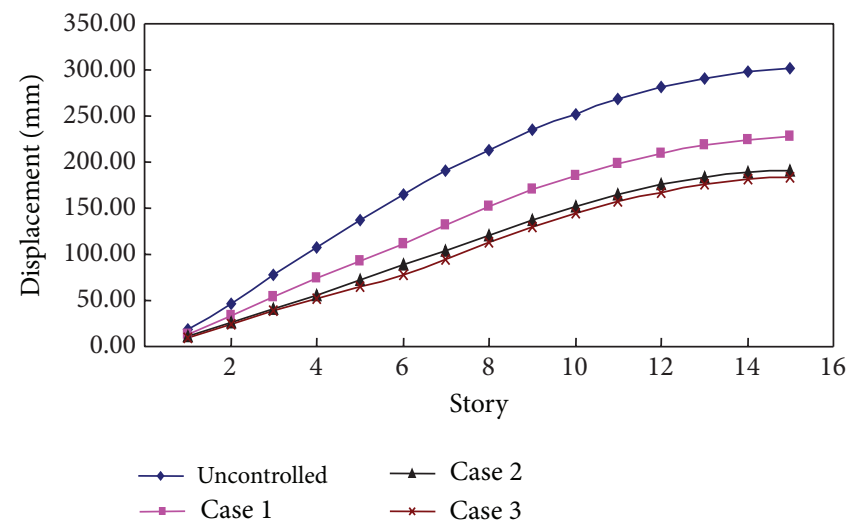

(d) Tianjin

FIGURE 6: Comparison of maximum displacements of structure with and without dampers.

TABLE 4: Number of dampers on each story for three cases.

\begin{tabular}{|c|c|c|c|c|c|c|c|c|c|c|c|}
\hline \multirow{2}{*}{ Case } & \multirow{2}{*}{ Earthquake } & \multicolumn{10}{|c|}{ Story } \\
\hline & & 1 & 2 & 3 & 4 & 5 & 6 & 7 & 8 & 9 & $10-15$ \\
\hline \multirow{4}{*}{1} & El Centro & 2 & 2 & 2 & 2 & 2 & 2 & 0 & 0 & 0 & 0 \\
\hline & Northridge & 2 & 2 & 2 & 2 & 2 & 2 & 0 & 0 & 0 & 0 \\
\hline & Imperial Valley & 2 & 2 & 2 & 2 & 0 & 0 & 0 & 2 & 2 & 0 \\
\hline & Tianjin & 2 & 2 & 2 & 2 & 2 & 2 & 0 & 0 & 0 & 0 \\
\hline \multirow{4}{*}{2} & El Centro & 4 & 4 & 4 & 4 & 2 & 2 & 0 & 0 & 0 & 0 \\
\hline & Northridge & 6 & 6 & 4 & 2 & 2 & 0 & 0 & 0 & 0 & 0 \\
\hline & Imperial Valley & 4 & 6 & 6 & 2 & 0 & 0 & 0 & 0 & 2 & 0 \\
\hline & Tianjin & 2 & 4 & 4 & 4 & 2 & 2 & 2 & 0 & 0 & 0 \\
\hline \multirow{4}{*}{3} & El Centro & 4 & 6 & 4 & 4 & 4 & 2 & 0 & 0 & 0 & 0 \\
\hline & Northridge & 6 & 6 & 6 & 4 & 2 & 0 & 0 & 0 & 0 & 0 \\
\hline & Imperial Valley & 6 & 6 & 6 & 4 & 0 & 0 & 0 & 0 & 2 & 0 \\
\hline & Tianjin & 4 & 4 & 4 & 4 & 4 & 4 & 0 & 0 & 0 & 0 \\
\hline
\end{tabular}

both good response reduction and economy. From the aspect of placement of dampers, it can be seen that dampers are mostly placed at the bottom, middle part, and side spans of the structure for the three cases.
TABLE 5: Story drift of the structure with dampers for case 1 (mm).

\begin{tabular}{lcccc}
\hline Story & El Centro & Northridge & Imperial Valley & Tianjin \\
\hline 1 & 6.38 & 9.19 & 7.09 & 13.06 \\
2 & 9.59 & 13.15 & 10.75 & 20.25 \\
3 & 10.02 & 12.76 & 10.86 & 20.44 \\
4 & 10.18 & 11.79 & 11.50 & 20.05 \\
5 & 10.08 & 10.66 & 13.19 & 18.77 \\
6 & 11.05 & 10.17 & 13.31 & 18.88 \\
7 & 12.37 & 12.04 & 10.82 & 20.44 \\
8 & 13.02 & 10.74 & 6.24 & 19.63 \\
9 & 13.77 & 8.99 & 4.63 & 17.95 \\
10 & 12.61 & 7.44 & 5.58 & 15.69 \\
11 & 11.16 & 6.34 & 5.25 & 13.74 \\
12 & 9.16 & 4.87 & 5.14 & 11.12 \\
13 & 7.02 & 3.66 & 4.63 & 8.40 \\
14 & 5.48 & 2.65 & 3.87 & 5.65 \\
15 & 3.32 & 1.87 & 2.22 & 3.02 \\
\hline
\end{tabular}

\section{Conclusions}

In this paper, an improved weight coefficient method is proposed and a new location index is given to optimize 


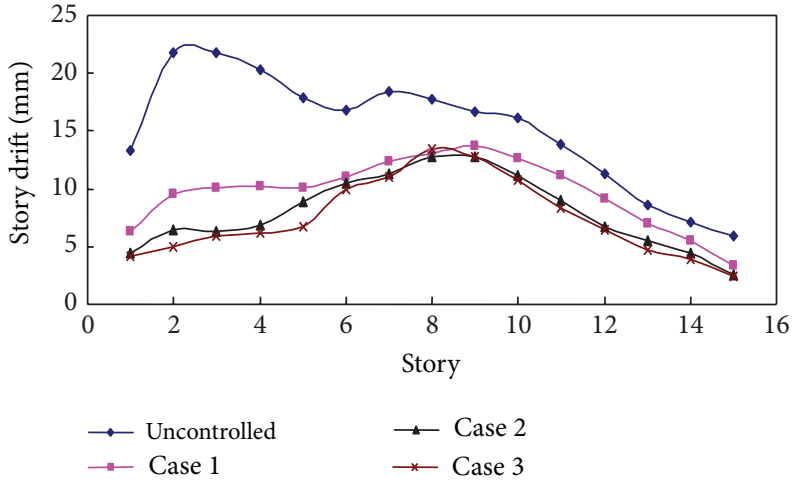

(a) El Centro

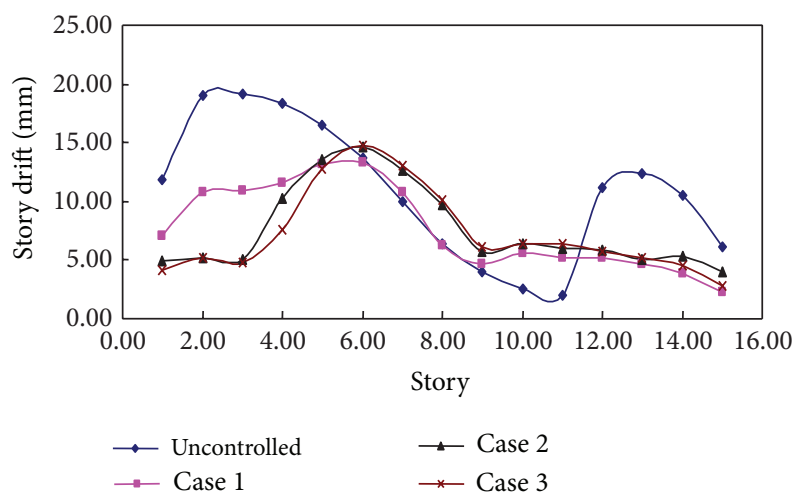

(c) Imperial Valley

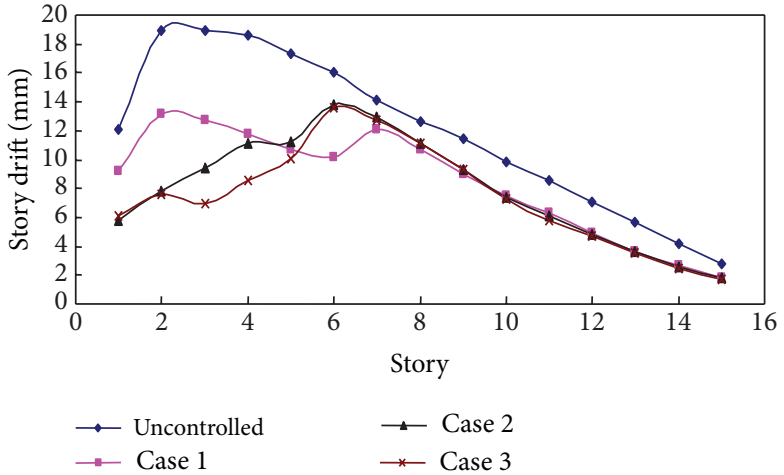

(b) Northridge

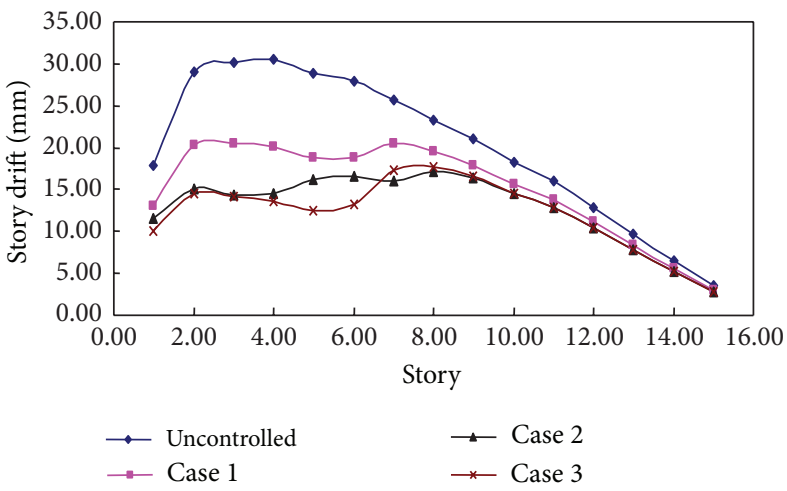

(d) Tianjin

FIGURE 7: Comparison of story drift of the structure with and without dampers.

TABLE 6: Story drift of the structure with dampers for case 2 ( $\mathrm{mm}$ ).

\begin{tabular}{lcccc}
\hline Story & El Centro & Northridge & Imperial Valley & Tianjin \\
\hline 1 & 4.50 & 5.82 & 4.93 & 11.47 \\
2 & 6.45 & 7.81 & 5.15 & 15.07 \\
3 & 6.29 & 9.42 & 5.11 & 14.33 \\
4 & 6.80 & 11.07 & 10.28 & 14.50 \\
5 & 8.92 & 11.25 & 13.53 & 16.23 \\
6 & 10.53 & 13.75 & 14.60 & 16.53 \\
7 & 11.28 & 12.90 & 12.65 & 16.01 \\
8 & 12.71 & 11.14 & 9.73 & 17.06 \\
9 & 12.81 & 9.26 & 5.74 & 16.37 \\
10 & 11.11 & 7.35 & 6.45 & 14.61 \\
11 & 8.97 & 6.07 & 6.04 & 12.81 \\
12 & 6.65 & 4.86 & 5.82 & 10.36 \\
13 & 5.48 & 3.59 & 4.99 & 7.84 \\
14 & 4.39 & 2.57 & 5.28 & 5.27 \\
15 & 2.54 & 1.78 & 4.00 & 2.82 \\
\hline
\end{tabular}

the reasonable number and locations of VEDs in structures based on the force analogy method. According to numerical simulations, a few conclusions can be drawn as follows.

(1) The structural displacement and story drift decrease a lot by using the raised optimal method, and the
TABLE 7: Story drift of the structure with dampers for case $3(\mathrm{~mm})$.

\begin{tabular}{lcccc}
\hline Story & El Centro & Northridge & Imperial Valley & Tianjin \\
\hline 1 & 4.23 & 6.12 & 4.14 & 10.00 \\
2 & 5.01 & 7.58 & 5.13 & 14.59 \\
3 & 5.91 & 7.00 & 4.82 & 14.16 \\
4 & 6.21 & 8.51 & 7.64 & 13.51 \\
5 & 6.72 & 10.11 & 12.71 & 12.51 \\
6 & 9.94 & 13.58 & 14.80 & 13.27 \\
7 & 11.07 & 12.70 & 13.08 & 17.22 \\
8 & 13.48 & 11.13 & 10.09 & 17.69 \\
9 & 12.72 & 9.25 & 6.09 & 16.59 \\
10 & 10.74 & 7.30 & 6.44 & 14.59 \\
11 & 8.37 & 5.75 & 6.42 & 12.87 \\
12 & 6.43 & 4.71 & 5.77 & 10.40 \\
13 & 4.72 & 3.48 & 5.25 & 7.86 \\
14 & 3.91 & 2.47 & 4.50 & 5.29 \\
15 & 2.43 & 1.71 & 2.81 & 2.83 \\
\hline
\end{tabular}

effects are optimal in lower layers. Furthermore, the distribution of displacements is more reasonable, which leads to a full use of materials.

(2) It can be concluded that a greater number of dampers is preferable, while, in practical applications, the 
amount of dampers should be confirmed wisely by setting the value of the location index with structural characteristics, dissipation effects, and economy all taken into consideration.

(3) The method presented here can not only specify the placement of dampers from layers to spans but also carry on the advantages of high efficiency and accuracy from the force analogy method, which is of great applicability.

(4) The improved weight coefficient method and new location index can be applied to the optimal design of the structure with other types of passive energy dissipation dampers.

\section{Acknowledgments}

This research work was jointly supported by the Science Fund for Creative Research Groups of the NSFC (Grant no. 51121005), the National Natural Science Foundation of China (Grant no. 51108064), and the Fundamental Research Funds for the Central Universities (Grant no. DUT13LK26). The authors would like to thank the reviewers for their careful reading of the paper and their constructive criticism.

\section{References}

[1] H. N. Li and S. Yan, "State-of-the-art review: researches and applications of structural control in China," Earthquake Engineering and Engineering Vibration, vol. 19, no. 1, pp. 107-112, 1999.

[2] G. Song, P. Qiao, V. Sethi, and A. Prasad, "Active vibration control of a smart pultruded fiber-reinforced polymer I-beam," Smart Materials and Structures, vol. 13, no. 4, pp. 819-827, 2004.

[3] G. Song and H. Gu, "Active vibration suppression of a composite I-beam using fuzzy positive position control," Smart Materials and Structures, vol. 14, no. 4, pp. 540-547, 2005.

[4] V. Sethi and G. Song, "Multimodal vibration control of a flexible structure using piezoceramic sensor and actuator," Journal of Intelligent Material Systems and Structures, vol. 19, no. 5, pp. 573582, 2008.

[5] H. Gu, G. Song, and H. Malki, "Chattering-free fuzzy adaptive robust sliding-mode vibration control of a smart flexible beam," Smart Materials and Structures, vol. 17, no. 3, Article ID 35007, 2008.

[6] V. Sethi, M. A. Franchek, and G. Song, "Active multimodal vibration suppression of a flexible structure with piezoceramic sensor and actuator by using loop shaping," Journal of Vibration and Control, vol. 17, no. 13, pp. 1994-2006, 2011.

[7] L. Y. Li, G. Song, and J. P. Ou, "Adaptive fuzzy sliding mode based active vibration control of a smart beam with mass uncertainty," Structural Control and Health Monitoring, vol. 18, no. 1, pp. 40-52, 2011.

[8] H. G. Natke and T. T. Soong, "Topological structural optimization under dynamic loads," in Optimization of Structural Systems and Applications, S. Hernandez and C. A. Brebbia, Eds., Computational Mechanics Publications, Southampton, UK, 1993.

[9] M. H. Milman and C. C. Chu, "Optimization methods for passive damper replacement and tuning," Journal of Guidance, Control, and Dynamics, vol. 17, no. 4, pp. 848-856, 1994.
[10] I. Takewaki, "Optimal damper placement for minimum transfer functions," Earthquake Engineering and Structural Dynamics, vol. 26, no. 11, pp. 1113-1124, 1997.

[11] I. Takewaki, S. Yoshitomi, K. Uetani, and M. Tsuji, "Non-monotonic optimal damper placement via steepest direction search," Earthquake Engineering and Structural Dynamics, vol. 28, pp. 655-670, 1999.

[12] M. P. Singh and L. M. Moreschi, "Optimal placement of dampers for passive response control," Earthquake Engineering and Structural Dynamics, vol. 31, no. 4, pp. 955-976, 2002.

[13] J. T. Qu and H. N. Li, "Optimal placement of passive energy dissipation devices by genetic algorithms," Mathematical Problems in Engineering, vol. 2012, Article ID 474282, 21 pages, 2012.

[14] Q. Zhang, W. J. Lou, and Y. Chen, "Parameter design and location optimum practical method of viscoelastic dampers," Structural Engineers, vol. 3, pp. 39-44, 2003.

[15] T. H. Lin, Theory of Inelastic Structures, John Wiley \& Sons, New York, NY, USA, 1968.

[16] G. C. Hart and K. K. F. Wong, Structural Dynamics for Structural Engineers, John Wiley \& Sons, New York, NY, USA, 2000.

[17] K. K. F. Wong and R. Yang, "Inelastic dynamic response of structures using force analogy method," Journal of Engineering Mechanics, vol. 125, no. 10, pp. 1190-1200, 1999.

[18] K. K. F. Wong and R. Yang, "Earthquake response and energy evaluation of inelastic structures," Journal of Engineering Mechanics, vol. 128, no. 3, pp. 308-317, 2002.

[19] A. F. Sun and J. P. Ou, "Lateral action patterns and their effects on pushover seismic analysis of steel tall buildings," Earthquake Engineering and Engineering Vibration, vol. 28, no. 4, pp. 88-93, 2008. 


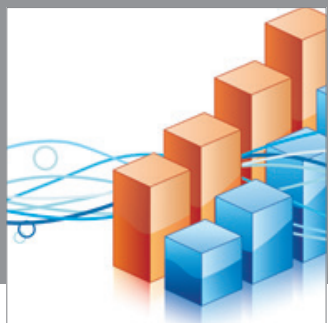

Advances in

Operations Research

mansans

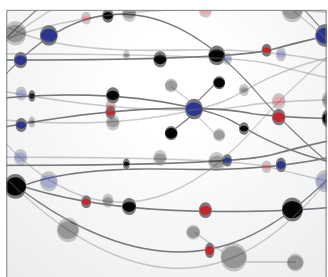

The Scientific World Journal
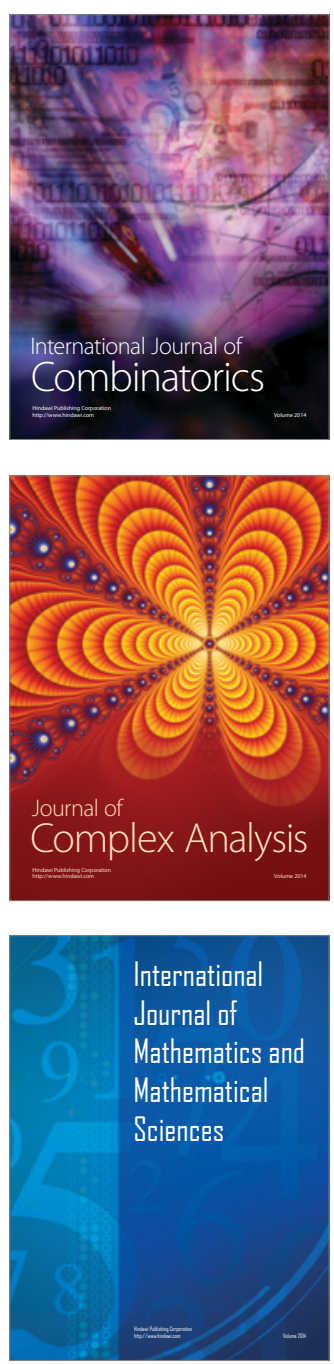
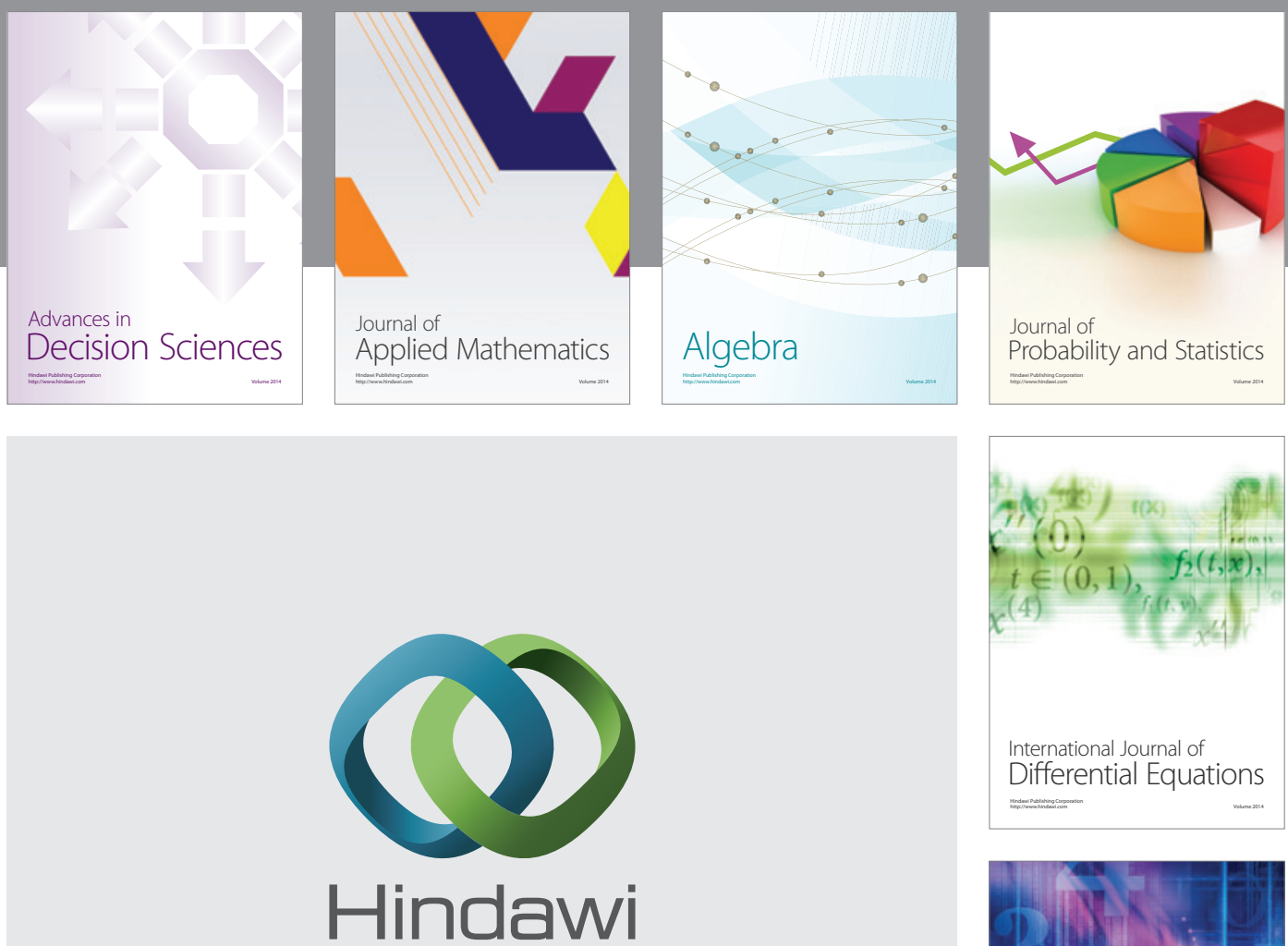

Submit your manuscripts at http://www.hindawi.com
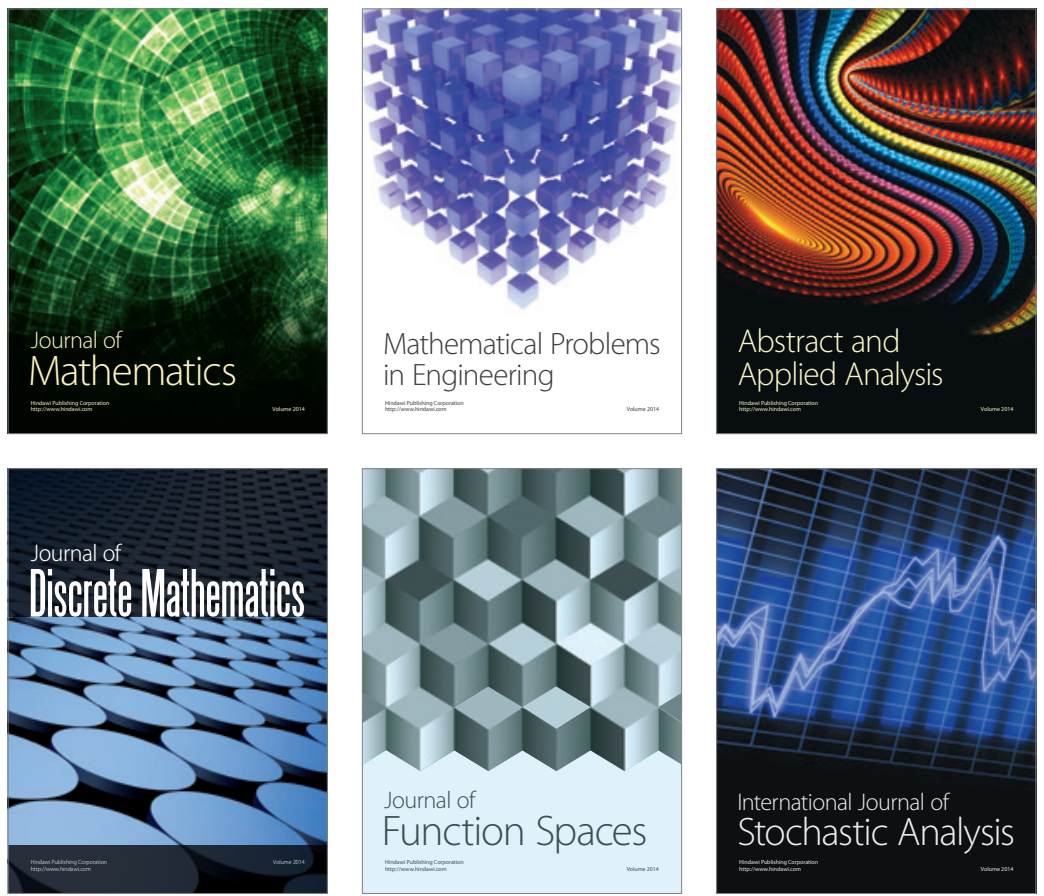

Journal of

Function Spaces

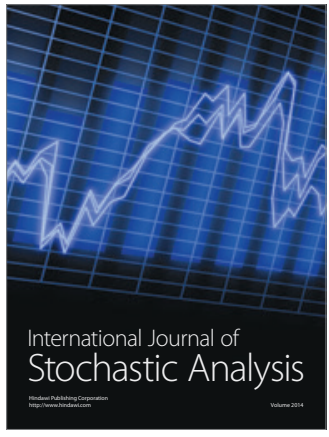

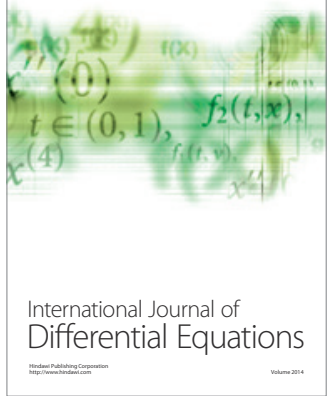
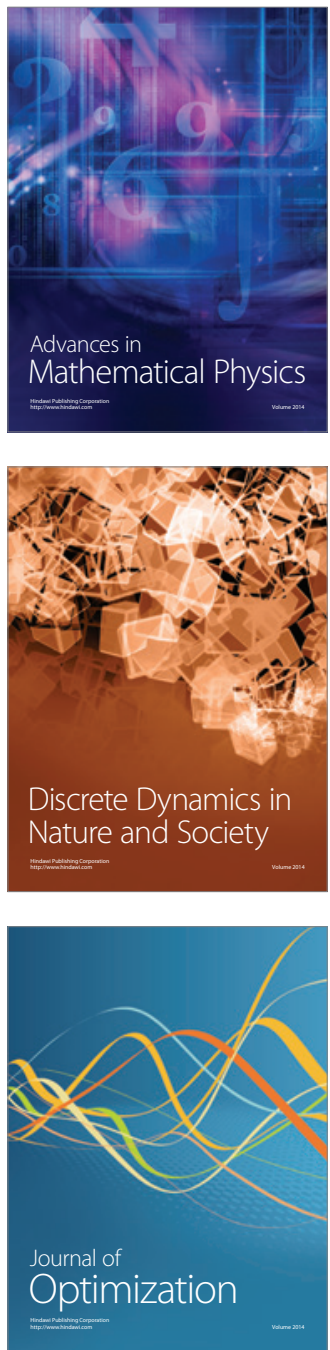